\title{
Serious Psychological Distress in U.S. Adults with Arthritis
}

\author{
Margaret Shih, MD, $P h D,{ }^{1}$ Jennifer M. Hootman, $P h D^{2}$ Tara W. Strine, $M P H_{,}{ }^{2}$ \\ Daniel P. Chapman, PhD, MSc, ${ }^{2}$ Teresa J. Brady, PhD ${ }^{2}$ \\ 'Office of Health Assessment and Epidemiology, Los Angeles County Department of Public Health, Los Angeles, CA, USA; \\ ${ }^{2}$ Division of Adult and Community Health, Centers for Disease Control and Prevention, Atlanta, GA, USA.
}

\begin{abstract}
BACKGROUND: Arthritis and mental health disorders are leading causes of disability commonly seen by health care providers. Several studies demonstrate a higher prevalence of anxiety and depression in persons with arthritis versus those without arthritis.
\end{abstract}

OBJECTIVES: Determine the national prevalence of serious psychological distress (SPD) and frequent anxiety or depression (FAD) in adults with arthritis, and in adults with arthritis, identify risk factors associated with SPD.

METHODS: Cross-sectional data from the 2002 National Health Interview Survey, an in-person household interview survey, were used to estimate the prevalence of SPD and FAD in adults with $(n=6,829)$ and without ( $n=20,676)$ arthritis. In adults with arthritis, the association between SPD and sociodemographic, clinical, and functional factors was evaluated using multivariable logistic regression.

RESULTS: The prevalence of SPD and FAD in adults with arthritis is significantly higher than in adults without arthritis $(5.6 \%$ vs $1.8 \%$ and $26.2 \%$ vs $10.7 \%, P<.001$, respectively). In adults with arthritis, SPD was significantly associated with younger age, lower socioeconomic status, divorce/separation, recurrent pain, physical inactivity, having functional or social limitations, and having comorbid medical conditions. Adults aged 18 to 44 years were 6.5 times more likely to report SPD than those 65 years or older, and adults with recurrent pain were 3 times more likely to report SPD than those without recurrent pain.

CONCLUSIONS: Serious psychological distress and FAD affect persons with arthritis and should be addressed in their treatment. Younger adults with arthritis, and those with recurrent pain or either functional or social limitations, may be at higher risk for SPD.

KEY WORDS: arthritis; mental health; depression; anxiety; psychological distress.

DOI: $10.1111 /$ j.1525-1497.2006.00573.x

J GEN INTERN MED 2006; 21:1160-1166.

A rthritis affected 43 million U.S. adults in $2002^{1}$ and is the leading cause of disability in the United States. ${ }^{2}$ Three of 10 working age adults with arthritis report some arthritis-attributable work limitation. ${ }^{1}$ Moreover, arthritis substantially impairs health-related quality of life, increasing both physically and mentally unhealthy days. ${ }^{3}$ Several studies have reported a higher prevalence of major depression, anxiety, and depressive symptoms in persons with arthritis. ${ }^{4-6}$ Notably, a recent study in a national sample of 54- to 65-year-olds estimated the attributable risk of major depression due to arthritis to be $18 \%$, comparable with the attributable risk due to heart disease. $^{7}$

No conflicts of interest to declare.

Address correspondence and requests for reprints to Dr. Shih: Office of Health Assessment and Epidemiology, Los Angeles County Department of Public Health, 313 N. Figueroa Street, Rm 127, Los Angeles, CA 90012 (e-mail: mshih@ladhs.org).
Both arthritis and mental health disorders are commonly seen by health care providers. Determining the prevalence of psychological distress in persons with arthritis is important because impaired mental health increases disability while decreasing quality of life, the ability to cope with illness, and responsiveness to treatment interventions. ${ }^{8-11}$ Furthermore, patients, particularly those with chronic medical conditions, place nearly as high a value on mental health as on physical health. ${ }^{12}$ Most prevalence studies thus far have been conducted in clinical settings, ${ }^{4}$ and only a few have assessed mental health in community samples. ${ }^{13,14}$

This investigation uses National Health Interview Survey (NHIS) data from 2002 to (1) determine the national prevalence of serious psychological distress (SPD) in the past 30 days $^{15}$ and frequent anxiety or depression (FAD) in the past 12 months in adults with self-reported doctor-diagnosed arthritis compared with adults without arthritis, and (2) in the subset of adults with arthritis, identify sociodemographic and other risk factors associated with SPD.

\section{METHODS}

\section{Data Source}

The NHIS is an ongoing, national, in-person household interview survey designed to represent the United States civilian, noninstitutionalized population, and uses a multistage, complex sampling design. ${ }^{16}$ The 2002 sample adult component used in this analysis included persons 18 years and older (median age of 45.2 years) and had a response rate of $74.3 \%$ $(n=31,044) .^{17}$

\section{Variables}

Arthritis. Patients with self-reported doctor-diagnosed arthritis ( $n=6,829)$, hereafter called arthritis, were identified by a "yes" response to the question, "Have you ever been told by a doctor or other health professional that you have some form of arthritis, rheumatoid arthritis, gout, lupus, or fibromyalgia?" This variable matches the $\mathrm{CDC}$ recommended definition of arthritis commonly used in disease surveillance reports. ${ }^{18} \mathrm{Re}-$ spondents who answered "no" and who did not have chronic joint symptoms (i.e., joint symptoms lasting 3 months or more) comprised the no arthritis group $(n=20,676)$. The 3,397 respondents with possible arthritis (i.e., chronic joint symptoms but no self-reported doctor-diagnosed arthritis) were excluded from the analysis because their arthritis status was not clear. Condition-specific data on type of arthritis were not

Manuscript received August 16, 2005

Initial editorial decision November 11, 2005

Final acceptance June 7, 2006 
available. Information regarding arthritis status was missing for 142 respondents.

SPD and FAD. Serious psychological distress is a nonspecific measure of psychological distress that has been psychometrically validated and shown to be able to discriminate community DSM-IV cases from noncases. ${ }^{19-21}$ It is intended to characterize having at least 1 mental disorder, such as major depressive disorder, generalized anxiety disorder, or schizophrenia, as well as having serious impairment in functioning. Serious psychological distress is determined using the Kessler 6 (K6) scale, which comprises 6 questions asking how often during the past 30 days a person felt "so sad that nothing could cheer them up," "nervous," "restless," "hopeless," "worthless," or that "everything was an effort." Responses are scored from 0 (none of time) to 4 (all the time) and summed to produce a total score (0 to 24), with a score of 13 or above used to define SPD. ${ }^{19}$ Only respondents who had complete information for all 6 questions were included. The 2002 NHIS also included a question about frequent symptoms of anxiety or depression; FAD in the past year was determined by a "yes" response to the question, "During the past 12 months, have you been frequently depressed or anxious?"

Covariates. Independent variables that have previously demonstrated an association with poor mental health in persons with arthritis were included in an initial multivariable logistic regression model..$^{5,13,14,21}$ These variables included age (18 to 44,45 to $64,65+$ ), gender, race or ethnicity (non-Hispanic white, non-Hispanic black, Hispanic, non-Hispanic other/ multiple race), education ( $\leq$ high school, $>$ high school), income $(<\$ 20,000, \$ 20,000+)$, marital status (married, widowed, divorced/separated, never married, living with partner), and body mass index $\left(\mathrm{BMI}=\right.$ weight $[\mathrm{kg}] /$ height $\left[\mathrm{m}^{2}\right]$; $<25$, underweight to normal weight; 25 to $<30$, overweight; $30+$, obese). Respondents reporting joint symptoms were asked to rate the severity of their joint pain during the past 30 days on a scale from 0 to 10 ( 0 to 3 , little to none; 4 to 6 , moderate; $7+$, severe). Respondents reporting no joint symptoms were categorized as having no (0) joint pain. Presence of chronic or recurrent pain during the past year, which was not restricted to joint pain, was assessed by the question, "During the past 12 months, have you had recurring pain?" Respondents who reported never participating in, or being unable to participate in, light, moderate, or vigorous physical activity for at least $10 \mathrm{~min} /$ occasion were defined as physically inactive. Respondents had at least 1 of 3 social/leisure limitations if they reported it was "very difficult" or they were "unable to" "Go out to things like shopping, movies, or sporting events"; "Participate in social activities such as visiting friends, attending clubs and meetings, going to parties"; or "Do things to relax at home or for leisure."

Respondents' health status was assessed by the presence of functional limitations, need for special equipment, and comorbid medical conditions. Respondents were categorized as having 0,1 to 3 , or 4 or more functional limitations by the number of times they responded "very difficult" or "unable to" for a list of 9 activities: walk a quarter mile, walk up 10 steps, stand for 2 hours, sit for 2 hours, stoop/bend/kneel, reach overhead, grasp small objects, lift/carry up to 10 pounds, and push/pull large objects. Having a health problem requiring the use of special equipment was determined by the question, "Do you now have any health problem that requires you to use special equipment, such as a cane, a wheelchair, a special bed, or a special telephone?"

Respondents were asked about the presence or absence of each of the following 16 medical conditions: hypertension, high cholesterol, back pain, neck pain, cardiovascular condition (angina, congestive heart failure, myocardial infarction, coronary heart disease, other heart condition), stroke, respiratory condition (asthma, emphysema, chronic bronchitis), thyroid problem, neurologic condition (multiple sclerosis, Parkinson's disease, neuropathy, seizures), cancer, diabetes, weak or failing kidneys, liver condition, vision problem (difficulty seeing, blindness, retinopathy, cataracts, glaucoma, macular degeneration), hearing impairment, or gastrointestinal condition (ulcer, inflammatory bowel, irritable bowel, severe constipation).

To create a variable for medical comorbidity, hierarchical logistic regression was performed to identify which self-reported medical conditions were associated with SPD. All conditions except cancer demonstrated a significant univariate association with SPD in persons with arthritis. Stepwise logistic regression using the remaining 15 conditions was performed at a significance level of 0.10. Testing for multicollinearity was conducted. Eight medical conditions were identified as being associated with SPD: respiratory conditions, gastrointestinal conditions, neurologic conditions, kidney disease, liver conditions, neck pain, back pain, and vision problems. A categorical variable indicating the number of associated comorbid conditions present ( 0 to 1,2 to 3,4 to 8 ) was created.

\section{Statistical Analyses}

Prevalence of SPD and FAD in adults with and without arthritis was estimated using sample adult weights. Using only the subsample of adults with arthritis, logistic regression analysis was performed to examine the association between SPD and covariates listed above. We chose to conduct regression analyses for SPD only. While FAD is of interest because it may provide an estimate of anxiety or depression over the past year, it involves use of a single question, and the authors were not aware of it having been previously validated. Crude odds ratios for SPD in adults with arthritis were calculated, and a series of multivariable logistic regression models were run, with the initial model including all covariates, including the categorical number of associated medical conditions. Sociodemographic variables and BMI were retained in the model whether or not they were significant. Joint pain in the past 30 days and need for special equipment were not significant in the intermediate model and thus were excluded from subsequent models. Tests for interactions of all remaining covariates with age, gender, and BMI, and between functional limitations and physical inactivity were conducted. No significant interactions were found. All reported prevalence estimates and adjusted and unadjusted odds ratios were calculated in SUDAAN (version 9.0.0; Research Triangle Institute, Research Triangle Park, $\mathrm{NC}$ ) to account for the complex sampling design. A significance level of $\alpha=0.05$ was used.

\section{RESULTS}

A description of the characteristics of the study population can be found in Table 1 . The prevalence of SPD in adults 
with arthritis (5.6\%) was nearly twice that of the overall U.S adult population $(3.0 \%)^{15}$ and more than 3 times that of persons without arthritis $(1.8 \%, P<.001)$. The prevalence of FAD was also significantly higher in adults with arthritis
(26.2\%) compared with those without arthritis $10.7 \%$, $P<.001)$. Among adults with arthritis, the prevalence of SPD was significantly higher among women, 18- to 44-yearolds, Hispanics and non-Hispanic others, and those who were

Table 1. Characteristics of the Study Population*, Overall and by Arthritis Status

\begin{tabular}{|c|c|c|c|}
\hline \multirow[t]{2}{*}{ Characteristic } & \multicolumn{3}{|c|}{ Weighted \% (95\% Cl) } \\
\hline & Overall $(n=31,044)$ & Arthritis $^{\dagger}(n=6,829)$ & No Arthritis ${ }^{\ddagger}(n=20,676)$ \\
\hline \multicolumn{4}{|l|}{ Age (y) } \\
\hline 18 to 44 & $52.5(51.7$ to 53.4$)$ & $19.8(18.7$ to 21.0$)$ & $63.1(62.1$ to 64.0$)$ \\
\hline 45 to 64 & $31.4(30.8$ to 32.1$)$ & 43.4 (41.9 to 44.8$)$ & 27.1 (26.3 to 27.9$)$ \\
\hline $65+$ & $16.1(15.5$ to 16.6$)$ & $36.8(35.4$ to 38.3$)$ & $9.9(9.4$ to 10.4$)$ \\
\hline \multicolumn{4}{|l|}{ Gender } \\
\hline Women & $52.0(51.3$ to 52.8$)$ & $60.6(59.1$ to 62.0$)$ & 50.1 (49.2 to 51.0$)$ \\
\hline \multicolumn{4}{|l|}{ Race/ethnicity } \\
\hline White, non-Hispanic & 72.7 (71.8 to 73.5$)$ & $80.4(79.1$ to 81.6$)$ & $69.6(68.7$ to 70.6$)$ \\
\hline Black, non-Hispanic & $11.2(10.6$ to 11.9$)$ & $10.5(9.6$ to 11.4$)$ & 11.6 (10.9 to 12.4$)$ \\
\hline Hispanic & $11.0(10.5$ to 11.6$)$ & 6.2 (5.6 to 6.8$)$ & 12.9 (12.3 to 13.6$)$ \\
\hline Other/multiple, non-Hispanic & $5.1(4.7$ to 5.5$)$ & $3.0(2.5$ to 3.6$)$ & 5.8 (5.4 to 6.3$)$ \\
\hline \multicolumn{4}{|l|}{ Education } \\
\hline$\leq$ High school & $45.9(45.1$ to 46.8$)$ & $52.4(50.9$ to 53.8$)$ & 43.9 (42.9 to 44.9$)$ \\
\hline \multicolumn{4}{|l|}{ Income } \\
\hline$<\$ 20,000$ & $18.2(17.5$ to 18.8$)$ & $23.2(22.0$ to 24.4$)$ & 16.7 (16.0 to 17.5$)$ \\
\hline \multicolumn{4}{|l|}{ Marital status } \\
\hline Married & $57.8(57.0$ to 58.6$)$ & $58.6(57.2$ to 60.1$)$ & 57.3 (56.3 to 58.3$)$ \\
\hline Widowed & $6.4(6.1$ to 6.6$)$ & 14.6 (13.8 to 15.5$)$ & 3.9 (3.7 to 4.2$)$ \\
\hline Divorced/separated & $10.3(10.0$ to 10.7$)$ & 14.1 (13.3 to 14.9$)$ & $9.0(8.6$ to 9.4$)$ \\
\hline Never married & $19.4(18.7$ to 20.2$)$ & 8.1 (7.3 to 9.0$)$ & $23.4(22.4$ to 24.3$)$ \\
\hline Living with partner & $5.8(5.5$ to 6.1$)$ & $4.5(3.9$ to 5.1$)$ & 6.1 (5.7 to 6.5$)$ \\
\hline \multicolumn{4}{|l|}{ Body mass index } \\
\hline Under/normal weight & 39.5 (38.7 to 40.2$)$ & $28.9(27.7$ to 30.2$)$ & 43.5 (42.6 to 44.4$)$ \\
\hline Overweight & 33.4 (32.7 to 34.0$)$ & 33.3 (32.0 to 34.6 ) & 33.1 (32.4 to 33.9 ) \\
\hline Obese & 22.4 (21.8 to 23.0$)$ & 33.2 (31.9 to 34.5$)$ & 18.4 (17.7 to 19.0$)$ \\
\hline \multicolumn{4}{|l|}{ Recurrent pain } \\
\hline Yes & $18.1(17.5$ to 18.7$)$ & $44.0(42.5$ to 45.5$)$ & $7.3(6.8$ to 7.7$)$ \\
\hline \multicolumn{4}{|l|}{ Joint pain } \\
\hline Little to none (0 to 3 ) & $78.3(77.7$ to 78.8$)$ & 42.5 (41.0 to 44.0 ) & 97.1 (96.8 to 97.3 ) \\
\hline Moderate (4 to 6 ) & $12.7(12.3$ to 13.2$)$ & $30.9(29.7$ to 32.2$)$ & 1.8 (1.6 to 2.0 ) \\
\hline Severe (7 to 10 ) & $8.2(7.8$ to 8.5$)$ & 24.6 (23.4 to 25.9$)$ & 1.0 (0.9 to 1.2$)$ \\
\hline \multicolumn{4}{|l|}{ Physically inactive } \\
\hline Yes & 36.7 (35.7 to 37.7$)$ & 42.9 (41.3 to 44.5$)$ & 35.7 (34.5 to 36.8 ) \\
\hline \multicolumn{4}{|l|}{ Need special equipment } \\
\hline Yes & 5.5 (5.2 to 5.8$)$ & 16.6 (15.7 to 17.7$)$ & $1.8(1.6$ to 2.1$)$ \\
\hline \multicolumn{4}{|l|}{ Functional limitations ${ }^{\S}$} \\
\hline 0 & 86 (85.4 to 86.5$)$ & 59.6 (58.0 to 61.1$)$ & 95.0 (94.6 to 95.4$)$ \\
\hline 1 to 3 & $8.8(8.4$ to 9.2$)$ & 23.8 (22.6 to 25.0 ) & 3.4 (3.1 to 3.7$)$ \\
\hline 4 or more & $5.0(4.7$ to 5.3$)$ & $16.2(15.2$ to 17.4$)$ & $1.4(1.2$ to 1.6$)$ \\
\hline \multicolumn{4}{|l|}{ Social/leisure limitations } \\
\hline 0 & $96.2(96.0$ to 96.5$)$ & $89.4(88.5$ to 90.2$)$ & 98.5 (98.3 to 98.7$)$ \\
\hline 1 or more & $3.4(3.1$ to 3.6$)$ & $9.9(9.1$ to 10.8$)$ & $1.2(1.1$ to 1.4$)$ \\
\hline \multicolumn{4}{|l|}{ Associated comorbid conditions $\|$} \\
\hline 0 to 1 & 76.7 (76.2 to 77.3$)$ & $50.3(49.0$ to 51.7$)$ & $87.1(86.5$ to 87.6$)$ \\
\hline 2 to 3 & 19.8 (19.3 to 20.3$)$ & 38.7 (37.4 to 40.0$)$ & 12.1 (11.6 to 12.6$)$ \\
\hline 4 to 8 & 3.4 (3.2 to 3.7$)$ & $11.0(10.2$ to 11.8$)$ & $0.8(0.7$ to 1.0$)$ \\
\hline \multicolumn{4}{|l|}{ Serious psychological distress (SPD) ${ }^{\#}$} \\
\hline Yes & $3.0(2.8$ to 3.3$)$ & $5.6(5.0$ to 6.3$)$ & $1.8(1.6$ to 2.0$)$ \\
\hline \multicolumn{4}{|l|}{ Frequent anxiety or depression (FAD) } \\
\hline Yes & $15.7(15.2$ to 16.3$)$ & $26.2(24.9$ to 27.5$)$ & $10.7(10.2$ to 11.2$)$ \\
\hline
\end{tabular}

* Data are from the 2002 National Health Interview Survey. Nonresponse was approximately $1.2 \%$ for education, $6.5 \%$ for income, $4.8 \%$ for body mass index, $2.1 \%$ for physical inactivity, $2.3 \%$ for SPD, and $<1 \%$ for other footnoted variables.

${ }^{\dagger}$ Respondents with self-reported doctor-diagnosed arthritis.

${ }^{\ddagger}$ Respondents who reported not having doctor-diagnosed arthritis or possible arthritis (i.e., joint symptoms $\geq 3$ months).

${ }^{\S}$ Number of rating the following 9 activities rated as very difficult or unable to do: walk a quarter mile, walk up 10 steps, stand for 2 hours, sit for 2 hours, stoop/bend/kneel, reach overhead, grasp small objects, lift/carry up to 10 pounds, and push/pull large objects.

"Number of rating the following 3 activities rated as very difficult or unable to do: "Go out to things like shopping, movies, or sporting events," "Participate in social activities such as visiting friends, attending clubs and meetings, going to parties," or "Do things to relax at home or for leisure."

${ }$ Number of comorbid medical conditions associated with SPD: respiratory conditions, gastrointestinal conditions, neurologic conditions, kidney disease, liver conditions, neck pain, back pain, and vision problems.

${ }^{\#}$ Serious psychological distress in the past 30 days (defined by a score $\geq 13$ on Kessler scale ${ }^{19}$ ). 
less educated, had a lower income, were divorced or separated, were obese, had recurrent pain, had moderate to severe joint pain, were physically inactive, needed special equipment, had 1 or more functional limitations, had 1 or more social/leisure limitations, or had 2 or more comorbid conditions associated with SPD (Table 2). The prevalence of FAD among these subgroups followed similar patterns as SPD (Appendix).

Table 2. Prevalence and Odds of Serious Psychological Distress (SPD) in Adults with Arthritis, by Selected Characteristics

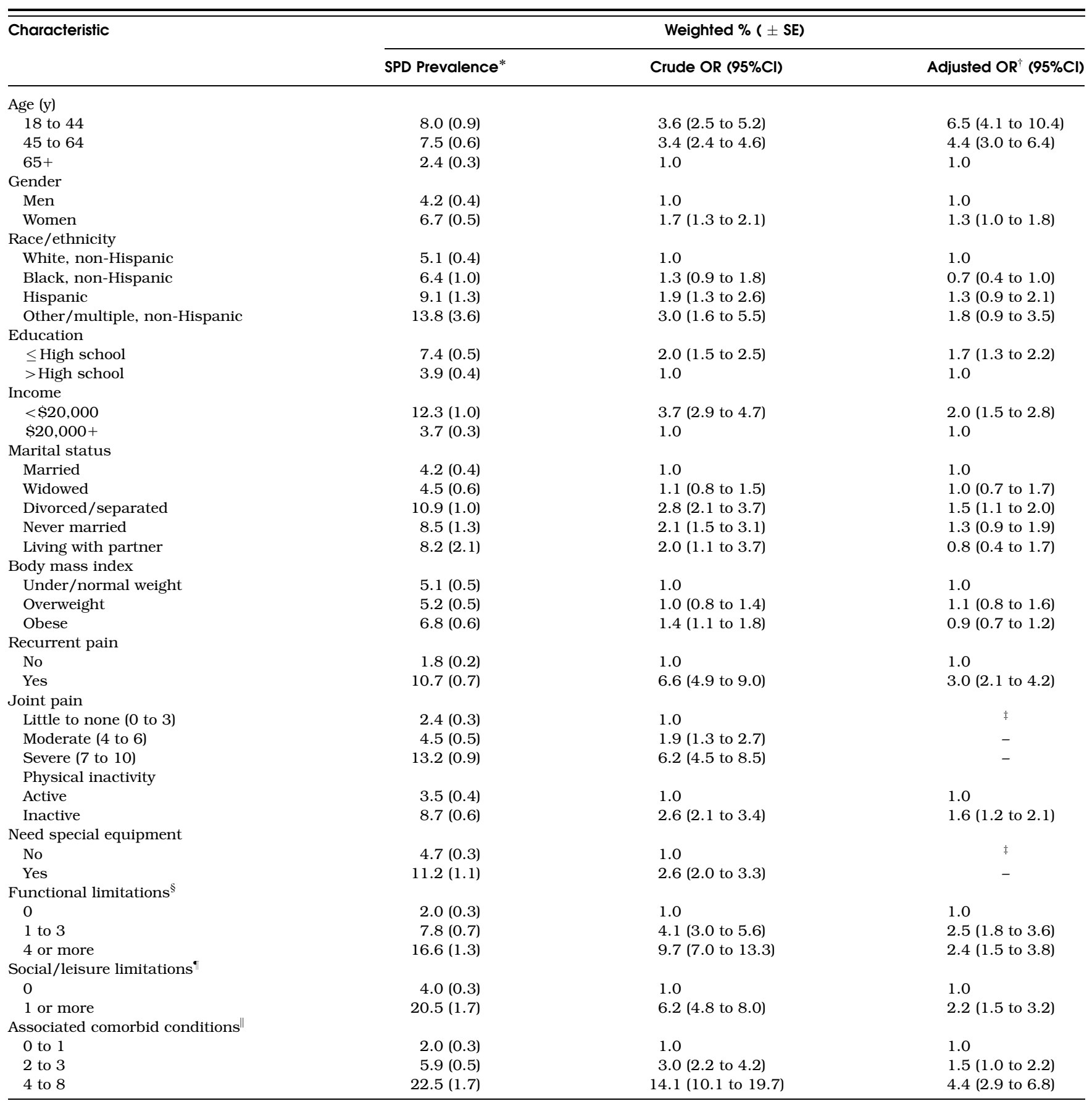

${ }^{*}$ Serious psychological distress in the past 30 days (defined by a score $\geq$ on Kessler scale ${ }^{19}$ ).

${ }^{\dagger}$ Adjusted for all other covariates in model except joint pain and need for special equipment.

${ }^{\ddagger}$ Not significant in multivariable logistic regression model and dropped from adjusted model.

${ }^{\S}$ Number of rating the following 9 activities rated as very difficult or unable to do: walk a quarter mile, walk up 10 steps, stand for 2 hours, sit for 2 hours, stoop/bend/kneel, reach overhead, grasp small objects, lift/carry up to 10 pounds, and push/pull large objects.

"Number of rating the following 3 activities rated as very difficult or unable to do: "Go out to things like shopping, movies, or sporting events," "Participate in social activities such as visiting friends, attending clubs and meetings, going to parties," or "Do things to relax at home or for leisure."

"Number of comorbid medical conditions associated with SPD: respiratory conditions, gastrointestinal conditions, neurologic conditions, kidney disease, liver conditions, neck pain, back pain, and vision problems. 
In adults with arthritis, age $<65$ years, lower education, lower income, divorce or separation, recurrent pain, physical inactivity, having 1 or more functional limitations or social/leisure limitations, and having 2 or more associated comorbid conditions were found to be associated with increased odds of SPD after adjustment for covariates using multivariable logistic regression modeling (Table 2). The association between age and SPD was particularly striking, with adults 18 to 44 years of age 6.5 (95\% CI 4.1 to 10.4 ) times more likely than those 65 years or older to have SPD. Female gender and obesity were no longer significant after adjustment, and non-Hispanic blacks were slightly less likely (adjusted OR $=0.7 ; 95 \%$ CI 0.4 to 1.0 ) to report SPD than non-Hispanic whites.

\section{DISCUSSION}

In this study, we found the national prevalence of both SPD and FAD to be significantly higher in adults with arthritis than in those without arthritis, with SPD prevalence 3 times higher and FAD prevalence 2.5 times higher. Frequent anxiety and depression in the past year (FAD) was common, with 1 in 4 adults with arthritis reporting FAD. After adjustment for covariates, SPD in the past 30 days was significantly associated with younger age, lower socioeconomic status, being divorced or separated, having recurrent pain, being physically inactive, and having more limitations or medical comorbidities in adults with arthritis.

These findings are consistent with other smaller studies of specialized populations that have found higher rates of anxiety, major depression, and depressive symptoms in persons with arthritis. ${ }^{5,6,22}$ One large community-based study ${ }^{14}$ found the prevalence of frequent mental distress ( $\geq 14$ mentally unhealthy days in the past 30 days) to be $13.4 \%$ among adults with arthritis who were 45 years and older. Although the results of that study are not directly comparable because different definitions of mental health and arthritis and a state-based data source were used, it corroborates the higher prevalence of mental distress in adults with arthritis compared with adults without arthritis.

Higher rates of depression and depressive symptoms in younger adults relative to older adults with arthritis have also been shown in previous studies. ${ }^{7,13,23}$ Although the reasons for this association remain unclear, studies in patients with rheumatoid arthritis ${ }^{22,24,25}$ suggest that depressive symptoms in younger adults and adolescents with arthritis are related to less effective coping strategies and higher perceived stress and pain. ${ }^{22,25}$ Because arthritis is a nonnormative event in younger adults, these higher rates of depression and depressive symptoms may be related to a greater perceived impact on family life, work, and leisure activities. ${ }^{26,27}$ Also, adults 18 to 44 years of age may be developing more systemic forms of arthritis, such as rheumatoid arthritis and systemic lupus erythematosus, which can have more severe manifestations. Finally, more recent birth cohorts have been found to be at increased risk for major depression. ${ }^{28}$ Longitudinal studies of mental health in persons with specific types of arthritis are needed to help discriminate between the roles of age versus birth cohort and to elucidate the relationship of age to psychological distress in specific types of arthritis.

Previous research has consistently shown depression to be associated with pain, functional impairment, and loss of valued activities in persons with arthritis ${ }^{4,7,29-32}$ and suggests that the relationship of pain and loss of function to depression is closely linked and bi-directional. ${ }^{33,34}$ Improvement of depression has been associated with improved functional status, ${ }^{35,36}$ and at least 1 randomized-controlled trial has shown that enhancing depression care in older adults with arthritis results in less pain and better function and quality of life. ${ }^{37}$ Furthermore, pain appears to be undertreated in depressed older adults with pain-related functional impairment. ${ }^{38} \mathrm{Im}$ proving pain management may not only directly benefit mental health and physical functioning but may also assist with increasing physical activity levels.

Lack of physical activity, which has been associated with depression and depressive symptoms in this and other studies, ${ }^{14,39}$ is another important modifiable risk factor in persons with arthritis that can mediate multiple contributing factors to mental well-being, including decreasing pain, improving function, delaying disability, and decreasing the risk of obesity and other chronic diseases that may further add to depressive symptoms. ${ }^{40-42}$ Several studies have shown exercise to be similarly effective to medication or cognitive behavioral therapy in treating major depression, ${ }^{43,44}$ but 1 meta-analysis, which was restricted to randomized-controlled trials of clinically depressed patients, cautions that although exercise appears to be effective in reducing depressive symptoms in the short term, studies with long-term follow-up are lacking. ${ }^{45}$ In persons with arthritis, increased physical activity has been shown to have significant mental health benefits ${ }^{46}$ and to be associated with fewer physically and mentally unhealthy days. ${ }^{47}$ Unfortunately, the prevalence of adults with arthritis who are not physically active remains high, ${ }^{48}$ while arthritisrelated physical activity counseling by health care providers remains low ${ }^{49}$ and represents a missed opportunity to help our patients and to meet Healthy People 2010 objectives. Existing evidence-based interventions such as the Arthritis Foundation Arthritis Self-Help Course, ${ }^{50}$ which is a group self-management education program, and the Arthritis Foundation Exercise Program, which is a community-based exercise program, have been shown to reduce pain and symptoms of anxiety and depression while improving function and activity levels. ${ }^{51}$ Efforts to expand access to these programs should be continued.

There are several limitations of the present study. One important limitation was that the data source did not contain information on what type of arthritis the respondent had, so we were not able to examine SPD or FAD in relation to specific rheumatic conditions. Second, due to the self-report nature of the data, which is subject to recall bias, patients with SPD or FAD may be more likely to recall being told by a health care provider that they have arthritis, resulting in misclassification bias. While data are not available to directly address this issue, 2 validation studies have shown the case definition used to be valid for public health surveillance and suggest that this is not a significant issue. ${ }^{52,53}$ Third, the use of cross-sectional survey data cannot be used to infer causation, and while we attempted to adjust for potential confounders as the data allowed, some confounders may not have been taken into account. Another limitation is that some of the K6 items, particularly the question asking whether "everything is an effort," may overlap with somatic symptoms of arthritis; however, the pattern of responses across individual items appeared similar in persons with and without arthritis. Finally, the survey population included only noninstitutionalized persons, so some adults with severe arthritis or depression may have been missed. 
This study has several important strengths. We provide the first national prevalence estimates for SPD and FAD in persons with arthritis, using a nationally representative sample of U.S. adults. Also, we were able to adjust for potential confounders in evaluating factors associated with SPD, including comorbid medical conditions, which is not possible with some data sources. Future research should focus on longitudinal studies of specific types of mental health problems, including depression and anxiety, in adults with different types of arthritis, specifically looking at the effects of age and physical activity. Younger adults with arthritis should be included in programs designed to help people with arthritis of all ages.

Mental health disorders remain underdiagnosed ${ }^{54}$ and undertreated ${ }^{55}$ in persons with arthritis, contributing to treatment noncompliance, poor response to treatment, higher disability rates, poor quality of life, and increased health care utilization among persons who seek medical care. There are many brief screening tools available for use in the clinical setting to facilitate diagnosis. ${ }^{56,57}$ Mental health impairment should be recognized, addressed, and followed-up by health care providers who care for adults with arthritis, especially among patients who are younger, have recurrent pain, or report limitations in either functional or social activities. Additional emphasis should be placed on physical activity counseling and pain management because these interventions may foster better mental health in addition to delaying physical disability.

This project was supported by a cooperative agreement from the Centers for Disease Control and Prevention through the Association of Teachers of Preventive Medicine.

\section{REFERENCES}

1. Bolen J, Sniezek J, Theis $\mathbf{K}$, et al. Racial/ethnic differences in the prevalence and impact of doctor-diagnosed arthritis - United States, 2002. Morb Mortal Wkly Rep. 2005;54:119-23.

2. McNeil J, Binette J. Bureau of Census, U.S. Department of Commerce, Centers for Disease Control and Prevention. Prevalence of disabilities and associated health conditions among adults-United States, 1999. Morb Mortal Wkly Rep. 2001;50:120-5.

3. Mili F, Helmick C, Zack M, Moriarty D. Health-related quality of life among adults reporting arthritis: Behavioral Risk Factor Surveillance System, 15 states and Puerto Rico, 1996-1999. J Rheumatol. 2003;30: 160-6.

4. Wells KB, Stewart A, Hays RD, et al. The functioning and well-being of depressed patients. Results from the Medical Outcomes Study. JAMA. 1989;262:914-9.

5. Dickens C, McGowan L, Clark-Carter D, Creed F. Depression in rheumatoid arthritis: a systematic review of the literature with meta-analysis. Psychosom Med. 2002;64:52-60.

6. el-Miedany YM, el-Rasheed AH. Is anxiety a more common disorder than depression in rheumatoid arthritis? Jt Bone Spine. 2002;69:300-6.

7. Dunlop D, Lyons J, Manheim L, Song J, Chang R. Arthritis and heart disease as risk factors for major depression: the role of functional limitations. Med Care. 2004;42:502-11.

8. McFarlane AC, Brooks PM. Determinants of disability in rheumatoid arthritis. Br J Rheumatol. 1988;27:7-14.

9. Parker JC, Wright GE. The implications of depression for pain and disability in rheumatoid arthritis. Arthritis Care Res. 1995;8:279-83.

10. Dimatteo MR, Lepper HS, Croghan TW. Depression is a risk factor for noncompliance with medical treatment: meta-analysis of the effects of anxiety and depression on patient adherence. Arch Intern Med. 2000; 160:2101-7.

11. Lowe B, Willand L, Eich W, et al. Psychiatric comorbidity and work disability in patients with inflammatory rheumatic diseases. Psychosom Med. 2004;66:395-402.
12. Sherbourne CD, Sturm R, Wells KB. What outcomes matter to patients? J Gen Intern Med. 1999;14:357-63.

13. Dexter P, Brandt K. Distribution and predictors of depressive symptoms in osteoarthritis. J Rheumatol. 1994;21:279-86.

14. Strine T, Hootman J, Okoro C, et al. Frequent mental distress status among adults with arthritis age 45 years and older, 2001. Arthritis Rheum. 2004;51:533-7.

15. National Center for Health Statistics. Serious Psychological Distress. Early Release of Selected Estimates Based on Data from the JanuaryJune 2004 National Health Interview Survey. Hyattsville, MD: U.S. Department of Health and Human Services, Centers for Disease Control and Prevention; 2005.

16. Botman SL, Moore TF, Moriarity CL, Parsons VL. Design and Estimation for the National Health Interview Survey, 1995-2004. Hyattsville, MD: National Center for Health Statistics; 2000 Vital Health Stat; 2: no. 130 .

17. National Center for Health Statistics. Data file documentation. National Health Interview Survey, 2002 (machine-readable data file and documentation). Hyattsville, MD: U.S. Department of Health and Human Services, Centers for Disease Control and Prevention, 2002.

18. Arthritis Program, National Center for Chronic Disease Prevention and Health Promotion, Centers for Disease Control and Prevention Arthritis Case Definition for Population Prevalence. Available at: http:// www.cdc.gov/arthritis/data_statistics/case_def.htm. Accessed April 10, 2006.

19. Kessler RC, Andrews G, Colpe LJ, et al. Short screening scales to monitor population prevalences and trends in non-specific psychological distress. Psychol Med. 2002;32:959-76.

20. Kessler RCP, Barker PRM, Colpe LJP, et al. Screening for serious mental illness in the general population. Arch Gen Psychiatry. 2003;60: 184-9.

21. Furukawa TA, Kessler RC, Slade T, Andrews G. The performance of the $\mathrm{K} 6$ and K10 screening scales for psychological distress in the Australian national survey of mental health and well-being. Psychol Med. 2003;33:357-62.

22. O'Malley PG, Jackson JL, Kroenke K, Yoon K, Hornstein E, Dennis GJ. The value of screening for psychiatric disorders in rheumatology referrals. Arch Intern Med. 1998;158:2357-62.

23. Wright GE, Parker JC, Smarr KL, Johnson JC, Hewett JE, Walker SE. Age, depressive symptoms, and rheumatoid arthritis. Arthritis Rheum. 1998;41:298-305.

24. Ramjeet J, Koutantji M, Barrett EM, Scott DGI. Coping and psychological adjustment in recent-onset inflammatory polyarthritis: the role of gender and age. Rheumatology. 2005;44:1166-8.

25. Adam V, St-Pierre Y, Fautrel B, Clarke AE, Duffy CM, Penrod JR. What is the impact of adolescent arthritis and rheumatism? Evidence from a national sample of Canadians. J Rheumatol. 2005;32:354-61.

26. Barlow JH, Cullen LA, Foster NE, Harrison K, Wade M. Does arthritis influence perceived ability to fulfill a parenting role? Perceptions of mothers, fathers and grandparents. Patient Educ Couns. 1999;37:141-51.

27. Murphy H, Dickens C, Creed F, Bernstein R. Depression, illness perception and coping in rheumatoid arthritis. J Psychosom Res. 1999;46:155-64.

28. Cross-National Collaborative Group. The changing rate of major depression. Cross-national comparisons. JAMA. 1992;268:3098-105.

29. Katz PP, Yelin EH. Life activities of persons with rheumatoid arthritis with and without depressive symptoms. Arthritis Care Res. 1994;7: 69-77.

30. Penninx BW, Leveille S, Ferrucci L, van Eijk JT, Guralnik JM. Exploring the effect of depression on physical disability: longitudinal evidence from the established populations for epidemiologic studies of the elderly. Am J Public Health. 1999;89:1346-52.

31. Lamb SE, Guralnik JM, Buchner DM, et al. Factors that modify the association between knee pain and mobility limitation in older women: the women's health and aging study. Ann Rheum Dis. 2000;59:331-7.

32. Neugebauer A, Katz PP, Pasch LA. Effect of valued activity disability, social comparisons, and satisfaction with ability on depressive symptoms in rheumatoid arthritis. Health Psychol. 2003;22:253-62.

33. Graney MJ. The reciprocal relationship between disability and depression. J Am Geriatr Soc. 2000;48:452-3.

34. Bruce ML. Depression and disability in late life: directions for future research. Am J Geriatr Psychiatry. 2001;9:102-12.

35. Von Korff M, Ormel J, Katon W, Lin EH. Disability and depression among high utilizers of health care. A Longitudinal ananlysis. Arch Gen Psychiatry. 1992;49:91-100. 
36. Coulehan JL, Schulberg HC, Block MR, Madonia MJ, Rodriguez E. Treating depressed primary care patients improves their physical, mental, and social functioning. Arch Intern Med. 1997;157:1113-20.

37. Lin EH, Katon W, Von Korff $\mathbf{M}$, et al. Effect of improving depression care on pain and functional outcomes among older adults with arthritis: a randomized controlled trial. JAMA. 2003;290:2428-9.

38. Unutzer J, Ferrell B, Lin EH, Marmon T. Pharmacotherapy of pain in depressed older adults. J Am Geriatr Soc. 2004;52:1916-22.

39. Farmer ME, Locke BZ, Moscicki EK, Dannenberg AL, Larson DB, Radloff LS. Physical activity and depressive symptoms: the NHANES I epidemiologic follow-up study. Am J Epidemiol. 1988;128:1340-51.

40. Stephens T. Physical activity and mental health in the United States and Canada: evidence from four population surveys. Prev Med. 1988;17:35-47.

41. Penninx BW, Rejeski WJ, Pandya J, et al. Exercise and depressive symptoms: a comparison of aerobic and resistance exercise effects on emotional and physical function in older persons with high and low depressive symptomatology. J Gerontol B Psychol Sci Soc Sci. 2002;57:124-32.

42. Penninx BW, Messier SP, Rejeski WJ, et al. Physical exercise and the prevention of disability in activities of daily living in older persons with osteoarthritis. Arch Intern Med. 2001;161:2309-16.

43. Craft LL, Landers DM. The effects of exercise on clinical depression and depression resulting from mental illness: a meta-regression analysis. J Sport Exer Psychol. 1998;20:339-57.

44. Babyak M, Blumenthal JA, Herman S, et al. Exercise treatment for major depression: maintenance of therapeutic benefit at 10 months. Psychosom Med. 2000;62:633-8.

45. Lawlor DA, Hopker SW. The effectiveness of exercise as an intervention in the management of depression: systematic review and meta-regression analysis of randomised controlled trials. BMJ. 2001;322:763-7.

46. Rejeski WJ, Ettinger WH Jr, Martin K, Morgan T. Treating disability in knee osteoarthritis with exercise therapy: a central role for self-efficacy and pain. Arthritis Care Res. 1998;11:94-101.

\section{Supplementary Material}

The following supplementary material is available for this article online at www.blackwell-synergy.com

Appendix. Prevalence of SPD and FAD in U.S. Adults, by Arthritis Status and Selected Characteristics, 2002 NHIS.
47. Abell JE, Hootman JM, Zack MM, Moriarty D, Helmick CG. Physical activity and health-related quality of life among people with arthritis. J Epidemiol Commun Health. 2005;59:380-5.

48. Hootman J, Macera C, Ham S, Helmick C, Sniezek J. Physical activity levels among the general U.S. adult population and in adults with and without arthritis. Arthritis Care Res. 2003;49:129-35.

49. Hootman JM, Langmaid G, Helmick CG, et al. Monitoring progress in arthritis management - United States and 25 states, 2003. Morb Mortal Wkly Rep. 2005;54:484-8.

50. Lorig KR, Holman HR. Arthritis self-management studies-a 12-year review. Health Educ Q. 1993;20:17-28.

51. Brady T, Kruger J, Helmick C, Callahan L, Boutaugh ML. Intervention programs for arthritis and other rheumatic diseases. Health Educ Behav. 2003;30:44-63.

52. Sacks J, Harrold L, Helmick C, Gurwitz J, Emani S, Yood R. Validation of a surveillance case definition for arthritis. J Rheumatol. 2005;32: 340-7.

53. Bombard J, Powell K, Martin L, Helmick C, Wilson W. Validity and reliability of self-reported arthritis, Georgia senior citizens, 2000-2001. Am J Prev Med. 2005;28:251-8.

54. Memel DS, Kirwan JR, Sharp DJ, Hehir M. General practitioners miss disability and anxiety as well as depression in their patients with osteoarthritis. Br J Gen Pract. 2000;50:645-8.

55. Wang PS, Lane M, Olfson M, Pincus HA, Wells KB, Kessler RC. Twelvemonth use of mental health services in the United States. Arch Gen Psychiatry. 2005;62:629-40.

56. Williams JW Jr, Noel PH, Cordes JA, Ramirez G, Pignone M. Is this patient clinically depressed? JAMA. 2002;287:1160-70.

57. Kroenke K, Spitzer RL, William JBW. The PHQ-9: validity of a brief depression severity measure. J Gen Intern Med. 2001;16:606-13. 